\title{
Effect of Acute Hypoxia on Vascular Responsiveness in Man
}

\author{
I. RESPONSIVENESS TO LOWER BODY NEGATIVE PRESSURE AND \\ ICE ON THE FOREHEAD
}

II. RESPONSES TO NOREPINEPHRINE AND ANGIOTENSIN

III. EFFECT OF HYPOXIA AND HYPOCAPNIA

\author{
Donald D. Heistad and Robert C. WheELER \\ - From the Physiology Laboratory, U. S. Army Research Institute of Environmental Medicine, \\ Natick, Massachusetts 01760
}

\begin{abstract}
A B S T R A C T An effect of hypoxemia on vascular responsiveness and blood pressure regulation has not been demonstrated in man. The response of forearm resistance vessels to several vasoconstrictor stimuli was compared during normoxia and acute hypoxia. Forearm vasoconstrictor responses to lower body negative pressure and to the application of ice to the forehead, which are neurogenic stimuli, were decreased during acute hypoxia. Lower body negative pressure caused a decrease in mean arterial pressure during hypoxia, but not during normoxia. Because norepinephrine is the neurotransmitter released during reflex vasoconstriction, we considered the possibility that decreased responsiveness to norepinephrine might be one mechanism for diminished responses to lower body negative pressure and ice on the forehead during hypoxia. Hypoxia decreased the response of forearm resistance vessels to infusions of norepinephrine and angiotensin into the brachial artery. In addition, the effectiveness of intravenous infusions of norepinephrine in elevating mean arterial pressure was decreased during hypoxia. Since exposure to acute hypoxia stimulates hyperventilation and hypocapnia, experiments were done to determine the contribution of hypocapnia during hypoxia to the decreased vasoconstriction. The results indicate that hypocapnia may diminish the vascular response to some stimuli, but the reduction in oxygen appears to be the primary mechanism for decreased vasoconstrictor responses during acute hypoxia.
\end{abstract}

This work was presented in part at the Annual Meeting of the American Federation for Clinical Research, Atlantic City, N. J., 3 May 1969. A preliminary report has appeared in abstract form (1).

Received for publication 29 October 1969 and in revised form 29 November 1969.

\section{INTRODUCTION}

Hypoxemia is commonly observed in patients with pulmonary disease, patients in shock, after a myocardial infarction (2), and in normal persons at high altitude. Observations in animals indicate that hypoxia may interfere with adrenergic responses. Skinner and Costin (3), using a perfused dog gracilis muscle preparation, found decreased responses to sympathetic nerve stimulation during hypoxia. Gowdey (4) reported that the pressor response of the cat to intravenous norepinephrine was greatly reduced at a simulated altitude of 20,000 feet. Indirect evidence in man suggests that hypoxia may alter blood pressure regulation (5). Reduced responsiveness to adrenergic stimuli similar to that demonstrated in animals might contribute to the hypotensive states observed in man in association with hypoxia.

The present experiments were done to test the hypothesis that hypoxia may interfere with the pressor and vasoconstrictor effects of adrenergic stimulation in man. Three studies were carried out. The first was done to observe the effect of hypoxia on responsiveness to lower body negative pressure and to the application of ice to the forehead. We found that hypoxia decreased the vasoconstriction induced by lower body negative pressure or by the application of ice to the forehead. These stimuli are mediated primarily through neurogenic reflexes $(6,7)$. Since norepinephrine is the neurotransmitter released during neurogenic vasoconstriction, in the second study we considered the possibility that hypoxia reduces responsiveness to norepinephrine. In the third study we assessed the contribution of hypocapnia, which is associated with the hyperventilation of hypoxia, to the altered responsiveness. 
I

\section{Responsiveness to lower body negative pressure and ice on the forehead}

\section{METHODS}

We studied 12 healthy men, 19-24 yr of age. The studies were done with the subject lying supine in a warm room $\left(80^{\circ} \mathrm{F}\right)$. The lower half of the body was enclosed in an air-tight box to the level of the iliac crests.

Blood pressure was determined by auscultation at $30-\mathrm{sec}$ intervals. Forearm blood flow was measured with a water plethysmograph (8). The segment of the forearm within the plethysmograph was at heart level. The water surrounding the arm was at $33^{\circ} \mathrm{C}$. A pneumatic cuff was placed around the upper arm and inflated intermittently above venous pressure for 8-12 sec. An increase in volume of the forearm within the plethysmograph displaced water in an open tube at the top of the plethysmograph, so that changes in arm volume were measured by a Statham strain gauge as a change in hydrostatic pressure. The rate of increase in volume of the forearm during intermittent venous occlusion indicates blood flow. In 8 of the 12 subjects blood flow to the hand was measured on the same arm, using a water plethysmograph. A second pneumatic cuff was placed around the wrist between the two plethysmographs. The wrist cuff was inflated at the same time as the upper arm cuff, and at the same pressure. The cuff produced venous occlusion at the wrist, allowing measurement of the rate of increase of volume in the hand and also preventing return of blood from the hand to the forearm during the period of forearm blood flow measurement (Fig. 1). In the four subjects in whom hand blood flow was not measured, a pneumatic cuff was placed around the wrist and inflated to suprasystolic pressure during the period of measurement to exclude con- tribution of hand blood flow from the measurement of forearm flow.

Each subject breathed three gas mixtures through a Rudolph valve: room air, $12 \%$ oxygen (in nitrogen), and $10 \%$ oxygen. Since the three gas mixtures can be given in six possible sequences, 2 of 12 subjects received each sequence. The gases were breathed for $16 \mathrm{~min}$, with a 10 -min rest period between each gas. After breathing each gas for $5 \mathrm{~min}$, control measurements were taken for $3 \mathrm{~min}$, and then the response to reflex vasoconstrictor stimuli was studied. The pressure within the suction box surrounding the lower body was reduced to $40 \mathrm{~mm} \mathrm{Hg}$ below atmospheric pressure, and maintained for $1.5 \mathrm{~min}$. Lower body negative pressure induces constriction of forearm resistance vessels $(7,9,10)$, apparently by pooling of blood in the lower extremities. Lower body negative pressure was applied twice while breathing each gas mixture, separated by a $1.5-\mathrm{min}$ rest period, and after a 2 min rest period a plastic bag of ice was applied to the forehead for $1 \mathrm{~min}$.

Blood flow to the forearm and hand were calculated from the rate of increase in the volume of the forearm or hand during venous occlusion and expressed in milliliters per minute per $100 \mathrm{ml}$ of forearm or hand. About four blood flow curves were obtained each minute. Values were not obtained for blood flow (or blood pressure) during the first $30 \mathrm{sec}$ of lower body negative pressure or of application of ice to the forehead, to avoid a rapidly shifting base line and to observe maximum responses. Values were averaged for the two periods of lower body negative pressure while breathing each gas. Forearm vascular resistance was derived by dividing mean arterial pressure by forearm blood flow and expressed in $\mathrm{mm} \mathrm{Hg}$ per milliliter per minute per 100 $\mathrm{ml}$. Mean arterial pressure was derived by adding one-third of the pulse pressure to the diastolic pressure (11).

Statistical comparisons were made by paired $t$ test analyses, comparing values while breathing air or $12 \%$ oxygen, and air or $10 \%$ oxygen.

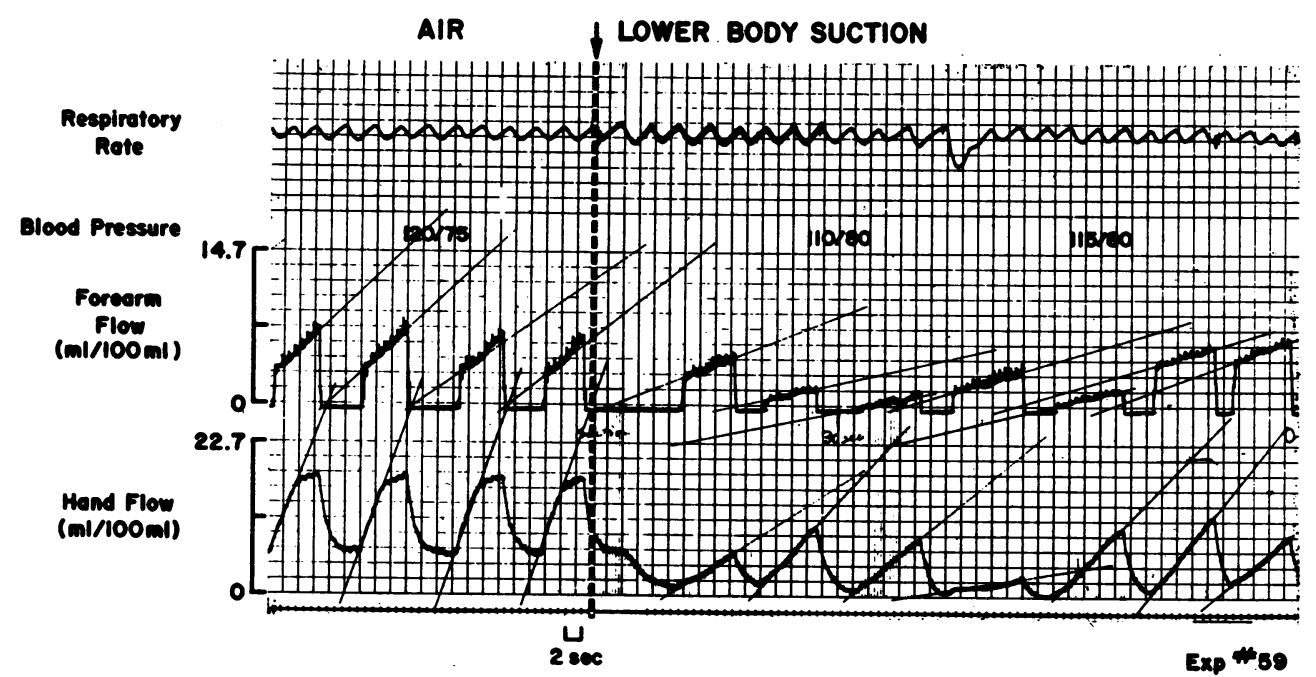

FIGURE 1 Changes in respiratory rate, systemic arterial pressure, forearm volume, and hand volume before and during lower body negative pressure while breathing room air. The slopes of the forearm and hand volume curves were used to calculate forearm and hand blood flow in milliliters per minute per $100 \mathrm{ml}$ of forearm or hand. Lower body negative pressure caused a minimal increase in mean arterial pressure (with a narrowing of pulse pressure) and decreased forearm and hand blood flow. 
TABLE I

Mean Arterial Blood Pressure in Response to Lower Body Negative Pressure, and Ice on the Forehead while Breathing Air, $12 \%$ Oxygen, and $10 \%$ Oxygen*

\begin{tabular}{|c|c|c|c|c|c|c|c|c|c|}
\hline \multirow[b]{2}{*}{ Subjects } & \multicolumn{3}{|c|}{ Air } & \multicolumn{3}{|c|}{$12 \% \mathrm{O}_{2}$} & \multicolumn{3}{|c|}{$10 \% \mathrm{O}_{2}$} \\
\hline & Con & LBNP & Ice & Con & LBNP & Ice & Con & LBNP & Ice \\
\hline & \multicolumn{3}{|c|}{$m m \mathrm{Hg}$} & \multicolumn{3}{|c|}{$m m \mathrm{Hg}$} & \multicolumn{3}{|c|}{$m m \mathrm{Hg}$} \\
\hline W. C. & 95 & 95 & 97 & 88 & 75 & 95 & 83 & 73 & 95 \\
\hline T. Ki. & 78 & 84 & 97 & 82 & 82 & 97 & 85 & 83 & 102 \\
\hline J. R. & 82 & 83 & 102 & 83 & 81 & 93 & 83 & 79 & 88 \\
\hline J. J. & 83 & 77 & 93 & 85 & 79 & 92 & 83 & 73 & 93 \\
\hline T. T. & 82 & 85 & 107 & 96 & 95 & 107 & 90 & 90 & 97 \\
\hline E. S. & 85 & 91 & 95 & 83 & 84 & 95 & 95 & 82 & 103 \\
\hline G. M. & 90 & 93 & 105 & 90 & 85 & 103 & 95 & 83 & 108 \\
\hline D. R. & 87 & 89 & 92 & 88 & 85 & 92 & 82 & 74 & 93 \\
\hline W. H. & 85 & 85 & 92 & 87 & 87 & 92 & 87 & 80 & 90 \\
\hline L. B. & 94 & 95 & 95 & 95 & 87 & 102 & 90 & 51 & 103 \\
\hline T. Ks. & 90 & 91 & 95 & 90 & 87 & 97 & 93 & 70 & 102 \\
\hline J. I. & 90 & 99 & 103 & 93 & 96 & 103 & 103 & 98 & 110 \\
\hline Mean & 86.7 & 89.0 & 97.6 & 88.4 & 85.3 & 97.2 & 89.2 & 78.0 & 98.7 \\
\hline $\mathrm{SE}$ & 1.5 & 1.8 & 1.5 & 1.4 & 1.7 & 1.5 & 1.9 & 3.4 & 2.0 \\
\hline$P \ddagger$ & & & & $>0.05$ & $<0.001$ & $>0.05$ & $>0.05$ & $<0.001$ & $>0.05$ \\
\hline
\end{tabular}

* Con refers to control (or "resting") observations, LBNP refers to lower body negative pressure, and Ice to application of Ice to the forehead.

$\ddagger \mathrm{P}$ values for control values refer to significance of difference of control values while breathing $12 \%$ or $10 \%$ oxygen from control values while breathing air. $P$ values for LBNP and Ice refer to significance of difference between change in mean arterial pressure caused by LBNP or Ice while breathing air or $12 \%$ oxygen and air or $10 \%$ oxygen.

TABLE II

Forearm Vascular Resistance in Response to Lower Body Negative Pressure and Ice on the Forehead while Breathing Air, $12 \%$ Oxygen, and $10 \%$ Oxygen*

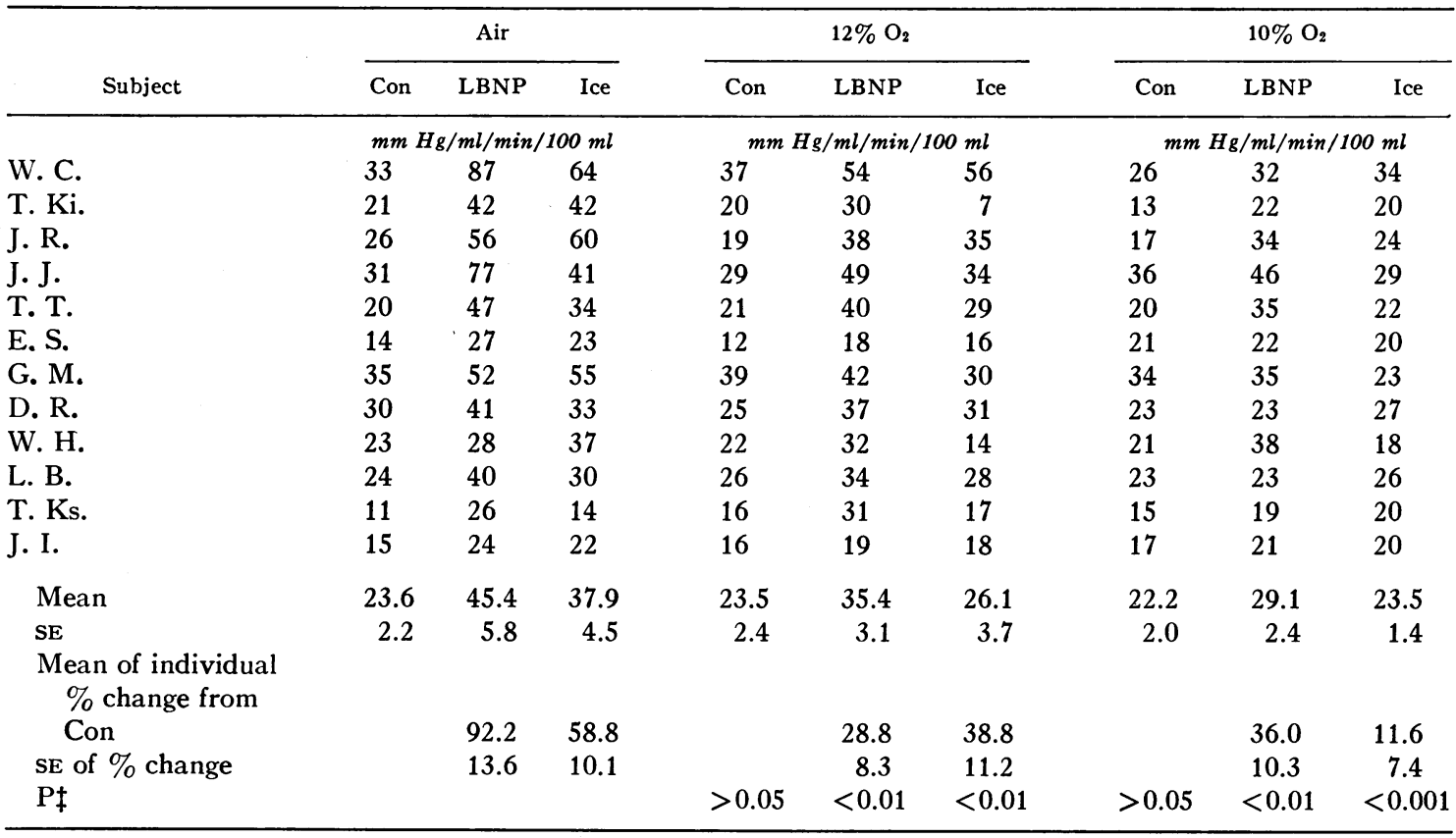

* See footnote to Table I.

$\ddagger$ See footnote $\ddagger$ to Table I. 
TABLE III

Forearm and Hand Blood Flow While Breathing Air, $12 \%$ Oxygen, and $10 \%$ Oxygen*

\begin{tabular}{|c|c|c|c|c|c|c|}
\hline \multirow[b]{2}{*}{ Subject } & \multicolumn{3}{|c|}{ Forearm blood flow } & \multicolumn{3}{|c|}{ Hand blood flow } \\
\hline & Air & $12 \% \mathrm{O}_{2}$ & $10 \% \mathrm{O}_{2}$ & Air & $12 \% \mathrm{O}_{2}$ & $10 \% \mathrm{O}$ \\
\hline & \multicolumn{3}{|c|}{$\mathrm{ml} / 100 \mathrm{ml}$} & \multicolumn{3}{|c|}{$\mathrm{ml} / 100 \mathrm{ml}$} \\
\hline W. C. & 2.9 & 2.4 & 3.2 & & & \\
\hline T. Ki. & 3.7 & 4.2 & 6.4 & & & \\
\hline J. R. & 3.1 & 4.3 & 5.0 & & & \\
\hline J. J. & 2.7 & 2.9 & 2.3 & & & \\
\hline T. T. & 4.1 & 4.6 & 4.4 & 23.0 & 16.8 & 16.9 \\
\hline E. S. & 5.9 & 7.0 & 4.6 & 10.4 & 9.0 & 5.3 \\
\hline G. M. & 2.6 & 2.3 & 2.8 & 9.3 & 11.1 & 5.4 \\
\hline D. R. & 2.9 & 3.5 & 3.6 & 14.9 & 14.2 & 17.3 \\
\hline W. H. & 3.7 & 4.0 & 4.1 & 10.7 & 9.6 & 11.4 \\
\hline L. B. & 3.9 & 3.7 & 3.9 & 26.8 & 29.1 & 21.7 \\
\hline T. Ks. & 8.2 & 5.6 & 6.1 & 18.4 & 9.5 & 8.6 \\
\hline J. I. & 5.9 & 5.8 & 6.1 & 16.3 & 14.4 & 14.9 \\
\hline Mean & 4.13 & 4.19 & 4.38 & 16.22 & 14.21 & 12.69 \\
\hline SE & 0.49 & 0.41 & 0.38 & 2.22 & 2.35 & 2.12 \\
\hline$P \ddagger$ & & $>0.05$ & $>0.05$ & & $>0.05$ & $<0.05$ \\
\hline
\end{tabular}

* Values are averages of $3 \mathrm{~min}$ of resting values while breathing each gas mixture.

$\ddagger$ Values refer to significance of difference of forearm or hand blood flow while breathing air or $12 \%$ oxygen and air or $10 \%$ oxygen.

\section{RESULTS}

Effect of hypoxia on resting blood pressure and vascular resistance. Mean arterial pressure and forearm vascular resistance were not significantly different while breathing air, $12 \%$ oxygen, or $10 \%$ oxygen (Tables I and II). Blood flow to the hand decreased during hypoxia; the reduction was statistically significant during the administration of $10 \%$ oxygen (Table III).

Responses to lower body negative pressure. Mean arterial pressure increased minimally during lower body negative pressure while breathing air, and fell during lower body negative pressure while breathing $12 \%$ or $10 \%$ oxygen (Table I). The increase in forearm vascular resistance during lower body negative pressure was significantly greater during normoxia than during either level of hypoxia (Table II).

Responses to application of ice to the forehead. The increase in mean arterial pressure during ice on the forehead was not significantly different while breathing air, $12 \%$ oxygen, and $10 \%$ oxygen (Table I). The increase in forearm vascular resistance which occurs during ice on the forehead while breathing air was markedly reduced during hypoxia (Table II).

\section{DISCUSSION}

These experiments indicate that constriction of forearm resistance vessels in response to lower body negative pressure is reduced during hypoxia. Reduction in vasoconstrictor responsiveness might explain the fall in arterial pressure observed with lower body negative pressure during hypoxia.

There may be an alternative to the interpretation that hypoxia reduces forearm vasoconstriction. We observed that hypoxia reduced blood flow to the hand, and tended to increase blood flow to the forearm, in agreement with previous studies (12-15). If the hand and the cutaneous portion of the forearm respond similarly to hypoxia, then it appears that cutaneous vasoconstriction occurs during hypoxia with dilatation of the vessels supplying the muscle bed, so that a greater proportion of blood flow to the forearm is distributed to the muscular portion of the forearm during hypoxia. If the vasoconstrictor response of vessels to muscle is less than that of cutaneous vessels in response to lower body negative pressure, the apparent decrease in forearm vasoconstriction by hypoxia might be due simply to the greater proportion of blood flow to the less responsive bed, the muscle. For this reason, we compared the changes in blood flow to the hand, which consists predominantly of skin flow (16), to the changes in the forearm, which consists of both skin and muscle flow. The decreases in flow during lower body negative pressure are virtually identical in the hand $(-38 \pm 5 \% \mathrm{SE})$ and forearm $(-37 \pm 5 \%)$, suggesting that the proportion of skin and muscle flow 
does not affect the response to lower body negative pressure. Thus the shift of blood flow within the forearm from cutaneous to musclar vessels during hypoxia would not account for the decreased forearm vasoconstrictor response to lower body negative pressure.

In response to application of ice to the forehead, blood flow to the hand decreased more $(-35 \pm 7 \%)$ than blood flow to the forearm $(-21 \% \pm 3 \%)$, confirming the greater responsiveness to ice of cutaneous vessels than vessels to muscle. Therefore, part of the reduction in responsiveness to ice during hypoxia might be caused by shifting of blood flow from skin to muscle by hypoxia. However, for shifts of blood flow during hypoxia to virtually abolish the forearm vasoconstriction during ice, as was observed in these experiments, the shifts would have to be much greater than those observed.

Intra-arterial guanethidine blocks the vasoconstrictor response to the application of ice to the forehead (6) and also to lower body negative pressure (in two experiments). Intra-arterial guanethidine is known to interrupt the transmission of neurogenic stimuli, but does not block the effects of circulating catecholamines. This suggests that the responses to the application of ice to the forehead and to lower body negative pressure are mediated predominantly through neurogenic reflexes (6, 7 ). Therefore the major new finding in this study is that hypoxia decreases the vasoconstrictor response to neurogenic reflexes.

The interference with neurogenic vasoconstriction by hypoxia causes a fall in arterial pressure during lower body negative pressure. Since the pooling of blood in the lower extremities during negative pressure simulates postural changes, the failure to maintain arterial pressure during negative pressure suggests the possibility of diminished postural compensatory mechanisms in the many diseases associated with hypoxia. In addition, decreased neurogenic vasoconstriction during acute hypoxia has important implications concerning compensation for acute blood loss, which is a neurogenic vasoconstrictor stimulus, during hypoxia associated with general anesthesia, pulmonary disease, and after a myocardial infarction.

\section{II}

\section{Responses to norepinephrine and angiotensin}

\section{METHODS}

We did 24 experiment on 15 healthy young men. The studies were done with the subject lying supine in a warm room $\left(80^{\circ} \mathrm{F}\right)$.

In 12 subjects the brachial artery was cannulated with a polyethylene cannula ( $\mathrm{PE} 90$ ) after superficial infiltration of the antecubital area over the artery with $2 \%$ xylocaine. The cannula was introduced approximately 2 inches into the artery, and connected to a pressure transducer and to a syringe for infusions of norepinephrine and angiotensin.

Forearm and hand blood were measured as described in the previous study in this report.

Each subject breathed three gas mixtures: room air, $12 \%$ oxygen, and $10 \%$ oxygen with a 10 min rest period between each gas. Since the three gases can be given in six possible sequences, 2 of the 12 subjects received each sequence.

TABLE IV

Arterial Blood Gas Oxygen and Carbon Dioxide Tension and $p H$ While Breathing Air, $12 \%$ Oxygen, and $10 \%$ Oxygen*

\begin{tabular}{|c|c|c|c|c|c|c|c|c|c|}
\hline \multirow[b]{2}{*}{ Subjects } & \multicolumn{3}{|c|}{$\mathrm{Po}_{2}$} & \multicolumn{3}{|c|}{$\mathrm{PcO}_{2}$} & \multicolumn{3}{|c|}{$\mathrm{pH}$} \\
\hline & Air & $12 \% \mathrm{O}_{2}$ & $10 \% \mathrm{O}_{2}$ & Air & $12 \% \mathrm{O}_{2}$ & $10 \% \mathrm{O}_{2}$ & Air & $12 \% \mathrm{O}_{2}$ & $10 \% \mathrm{O}_{2}$ \\
\hline & & $m m H g$ & & & $\mathrm{~mm} \mathrm{Hg}$ & & & & \\
\hline R. W. & 84.4 & 28.4 & 26.0 & 39.1 & 31.7 & 34.5 & 7.39 & 7.43 & 7.43 \\
\hline T. Ki. & 83.5 & 36.7 & 28.0 & 37.7 & 32.5 & 37.0 & 7.39 & 7.42 & 7.43 \\
\hline J. R. & 90.8 & 42.3 & 31.6 & 40.5 & 34.7 & 26.2 & 7.41 & 7.44 & 7.47 \\
\hline $\mathrm{J} . \mathrm{J}$. & 88.2 & 41.0 & 33.4 & 41.3 & 31.5 & 35.7 & 7.43 & 7.45 & 7.45 \\
\hline T. T. & 89.0 & 40.2 & 34.4 & 30.0 & 35.8 & 31.0 & 7.38 & 7.43 & 7.46 \\
\hline R. S. & 82.5 & 41.0 & 32.6 & 41.5 & 34.8 & 32.2 & 7.38 & 7.42 & 7.44 \\
\hline D. R. & 94.6 & 37.8 & 39.3 & 34.2 & 21.8 & 17.8 & 7.40 & 7.42 & 7.46 \\
\hline G. M. & 88.5 & 44.5 & 38.0 & 37.2 & 34.1 & 23.5 & 7.38 & 7.43 & 7.45 \\
\hline L. B. & 97.5 & 46.4 & 36.0 & 30.7 & 31.0 & 25.9 & & & \\
\hline M. R. & 95.9 & 39.5 & 31.1 & 30.2 & 31.1 & 27.2 & 7.44 & 7.44 & 7.47 \\
\hline D. M. & 91.0 & 51.0 & 51.7 & 30.8 & 19.4 & 20.2 & 7.47 & 7.46 & 7.50 \\
\hline Mean & 89.6 & 40.8 & 34.7 & 35.8 & 30.8 & 28.3 & 7.407 & 7.434 & 7.456 \\
\hline $\mathrm{SE}$ & 1.5 & 1.7 & 2.1 & 1.4 & 1.6 & 1.9 & 0.010 & 0.004 & 0.007 \\
\hline
\end{tabular}

* $\mathrm{Po}_{2}$ and $\mathrm{PCO}_{2}$ refer to arterial blood oxygen and carbon dioxide tension. 
TABLE V

Forearm Blood Flow in Response to Norepinephrine and Angiotensin into the Brachial Artery While Breathing Air, $12 \%$ Oxygen, and $10 \%$ Oxygen*

\begin{tabular}{|c|c|c|c|c|c|c|c|c|c|c|c|c|c|}
\hline \multirow[b]{2}{*}{ Subject } & \multicolumn{5}{|c|}{ Air } & \multicolumn{3}{|c|}{$12 \% \mathrm{O}_{2}$} & \multicolumn{5}{|c|}{$10 \% \mathrm{O}_{2}$} \\
\hline & Con $\ddagger$ & $\mathrm{NE}_{1}$ & $\mathrm{NE}_{2}$ & $\mathbf{A}_{1}$ & $\mathbf{A}_{2}$ & Con & $\mathrm{NE}_{1}$ & $\mathrm{NE}_{2}$ & Con $\ddagger$ & $\mathrm{NE}_{1}$ & $\mathrm{NE}_{2}$ & $\mathbf{A}_{1}$ & $A_{2}$ \\
\hline & \multicolumn{5}{|c|}{$\mathrm{ml} / 100 \mathrm{ml}$} & \multicolumn{3}{|c|}{$m l / 100 m l$} & \multicolumn{5}{|c|}{$\mathrm{ml} / 100 \mathrm{ml}$} \\
\hline R. W. & 1.4 & 1.0 & 1.1 & 1.0 & 0.7 & 1.9 & 1.5 & 1.6 & 1.6 & 1.1 & 1.5 & 1.7 & 1.7 \\
\hline T. K. & 3.0 & 1.8 & 1.6 & 1.7 & 1.4 & 3.4 & 2.6 & 2.4 & 5.2 & 3.1 & 3.1 & 2.9 & 3.1 \\
\hline J. R. & 4.4 & 3.1 & 2.8 & 2.5 & 2.5 & 3.9 & 2.6 & 2.6 & 4.4 & 2.8 & 3.2 & 3.2 & 3.1 \\
\hline J. J. & 3.9 & 2.4 & 2.2 & 2.1 & 2.9 & 3.4 & 2.5 & 2.4 & 4.5 & 3.4 & 3.3 & 3.2 & 2.5 \\
\hline T. T. & 3.2 & 2.1 & 1.7 & 2.2 & 1.8 & 6.1 & 4.7 & 3.4 & 5.1 & 4.5 & 3.7 & 2.9 & 2.6 \\
\hline R. S. & 4.1 & 3.9 & 3.4 & 2.7 & 2.4 & 5.4 & 5.2 & 4.5 & 4.0 & 3.7 & 4.0 & 3.2 & 3.8 \\
\hline G. M. & 3.4 & 2.1 & 1.9 & 2.6 & 2.2 & 2.8 & 1.7 & 1.9 & 3.1 & 2.2 & 2.3 & 2.4 & 2.4 \\
\hline D. $\mathbf{R}$. & 2.6 & 2.2 & 2.0 & 2.2 & 2.1 & 3.1 & 2.9 & 2.4 & 3.4 & 3.7 & 2.6 & 2.7 & 2.9 \\
\hline W. H. & 4.8 & 3.3 & 3.3 & 3.1 & 2.8 & 6.5 & 4.4 & 3.6 & 6.7 & 5.8 & 4.3 & 4.9 & 4.8 \\
\hline L. B. & 3.7 & 2.6 & 2.6 & 2.1 & 1.6 & 4.6 & 4.2 & 2.9 & 2.8 & 2.6 & 2.2 & 2.9 & 2.6 \\
\hline M. R. & 3.5 & 2.3 & 1.4 & 2.5 & 1.4 & 3.7 & 2.7 & 2.3 & 4.0 & 2.1 & 2.4 & 1.7 & 1.7 \\
\hline D. M. & 3.4 & 2.3 & 2.2 & 2.6 & 2.9 & 3.8 & 3.6 & 3.4 & 4.3 & 3.3 & $\ldots .2 .3$ & $\ldots \ldots \mathbf{3}$ & 3.2 \\
\hline Mean & 3.45 & 2.42 & 2.18 & 2.28 & 2.06 & 4.05 & 3.22 & 2.78 & 4.09 & 3.19 & 2.91 & $" 2.92$ & 2.78 \\
\hline $\mathbf{S E}$ & 0.26 & 0.22 & 0.21 & 0.16 & 0.20 & 0.39 & 0.34 & 0.23 & 0.38 & 0.35 & 0.24 & 0.24 & 0.23 \\
\hline \multicolumn{14}{|l|}{ Mean of individual } \\
\hline$\%$ change from Con & & 29.8 & 36.3 & 33.0 & 40.4 & & 20.8 & 29.5 & & 21.9 & 26.8 & 25.4 & 28.6 \\
\hline SE of $\%$ change & & 2.9 & 3.6 & 2.8 & 4.2 & & 3.5 & 3.2 & & 4.7 & 3.9 & 5.2 & 5.2 \\
\hline
\end{tabular}

* Con refers to control (or "resting") observations. $\mathrm{NE}_{1}$ and $\mathrm{NE}_{2}$ refer to the doses of norepinephrine and $\mathrm{A}_{1}$ and $\mathrm{A}_{2}$ to the doses of angiotensin : 75 and $150 \mathrm{ng} / \mathrm{min}$ respectively.

$\ddagger$ Individual control values during air and $10 \% \mathrm{O}_{2}$ are averages of the two control periods before norepinephrine and angiotensin infusions.

After breathing each gas for $5 \mathrm{~min}$, control measurements were made for $3 \mathrm{~min}$, and then either $l$-norepinephrine-bitartrate or angiotensin was infused into the brachial artery. The drug was infused with a Harvard constant infusion pump at a dose of $75 \mathrm{~m} \mu \mathrm{g} / \mathrm{min}$ (as the base) for $3 \mathrm{~min}$ and then at $150 \mathrm{~m} \mu \mathrm{g} / \mathrm{min}$ for $3 \mathrm{~min}$. The drugs were diluted in $5 \%$ dextrose in water and infused at 1.0 and $2.0 \mathrm{ml} / \mathrm{min}$. Norepinephrine was infused while each subject was breathing air, $12 \%$ oxygen, and $10 \%$ oxygen, and angiotensin was infused while breathing air and $10 \%$ oxygen. In six subjects

TABLE VI

Analysis of Variance of Forearm Responses to Norepinephrine and Angiotensin While Breathing Air and $10 \%$ Oxygen*

\begin{tabular}{lrrrc}
\hline & \multicolumn{5}{c}{ Decrease in forearm blood flow } \\
\cline { 2 - 5 } $\begin{array}{l}\text { Source of } \\
\text { variation }\end{array}$ & df & $\begin{array}{c}\text { Mean } \\
\text { square }\end{array}$ & \multicolumn{1}{c}{ F } & $P$ \\
\hline Subjects & 11 & 780 & & \\
Oxygen $\ddagger$ & 1 & 2035 & 9.37 & $<0.025$ \\
Drug dose & 1 & 724 & 15.69 & $<0.005$ \\
Drug§ & 1 & 241 & 1.37 & $>0.05$ \\
Error & 11 & 53.8 & & \\
\hline
\end{tabular}

* Analysis of variance was done on the per cent decrease in forearm flow to consider resting values as well as absolute reductions as described in the text.

$\ddagger$ Oxygen refers to variation among responses to drugs while breathing air and $10 \%$ oxygen.

$\S$ Drug refers to difference between responses to norepinephrine and angiotensin. norepinephrine was infused before angiotensin, and in six subjects the order was reversed.

An arterial blood sample was obtained after $6 \mathrm{~min}$ of breathing each gas. $\mathrm{PO}_{2}$ (oxygen tension), $\mathrm{PCO}_{2}$ (carbon dioxide tension), and $\mathrm{pH}$ were determined by a Corning model 16 blood gas system.

In 12 other experiments a No. 17 Intracath was inserted about 3 inches into the basilic vein and connected to a syringe for infusion of norepinephrine. Calf blood flow was measured with a water plethysmograph (17). A pneumatic cuff was placed around the ankle and inflated to suprasystolic pressure during the measurements to exclude the contribution of venous return from the foot to changes in calf volume. A pneumatic cuff was placed around the thigh and inflated intermittently for $10-15 \mathrm{sec}$ to pressures sufficient to produce venous occlusion. Blood pressure was determined by auscultation.

The subjects breathed room air, $12 \%$ oxygen, and $10 \%$ oxygen twice: 3 and $6 \mu \mathrm{g} / \mathrm{min}$ of norepinephrine (as the base) were infused into the basilic vein while breathing each gas mixture. The norepinephrine was diluted in $5 \%$ dextrose in water and infused with a Harvard pump. Statistical comparisons were made by analysis of variance.

\section{RESULTS}

Arterial blood oxygen and carbon dioxide tensions. Average arterial blood $\mathrm{Po}_{2}$ decreased from $90 \mathrm{~mm} \mathrm{Hg}$ while breathing air to $41 \mathrm{~mm} \mathrm{Hg}$ during $12 \%$ oxygen and $35 \mathrm{~mm} \mathrm{Hg}$ during $10 \%$ oxygen (Table IV). Accompanying the decrease in $\mathrm{Po}_{2}$ during hypoxia was a fall in $\mathrm{PCO}_{2}$ and a rise in $\mathrm{pH}$.

Effect of hypoxia on responsiveness to intraarterial norepinephrine and angiotensin The doses of norepi- 
TABLE VII

Mean Arterial Blood Pressure in Response to Intravenous Norepinephrine While Breathing Air, $12 \%$ Oxygen, and $10 \%$ Oxygen*

\begin{tabular}{|c|c|c|c|c|c|c|c|c|c|}
\hline \multirow[b]{2}{*}{ Subject } & \multicolumn{3}{|c|}{ Air } & \multicolumn{3}{|c|}{$12 \% \mathrm{O}_{2}$} & \multicolumn{3}{|c|}{$10 \% \Theta_{2}$} \\
\hline & Con & $\mathrm{NE}_{1}$ & $\mathrm{NE}_{2}$ & Con & $\mathrm{NE}_{1}$ & $\mathrm{NE}_{2}$ & Con & $\mathrm{NE}_{1}$ & $\mathrm{NE}_{2}$ \\
\hline & \multicolumn{3}{|c|}{$m m \mathrm{Hg}$} & \multicolumn{3}{|c|}{$m m \mathrm{Hg}$} & \multicolumn{3}{|c|}{$m m \mathrm{Hg}$} \\
\hline W. C. & 93 & 14 & 26 & 99 & 16 & 20 & 96 & 15 & 17 \\
\hline T. K. & 94 & 15 & 20 & 100 & 14 & 24 & 96 & 3 & 24 \\
\hline J. R. & 86 & 11 & 8 & 89 & 9 & 21 & 82 & 9 & 17 \\
\hline T. T. & 90 & 11 & 16 & 88 & 1 & 8 & 91 & 6 & 10 \\
\hline J. J. & 83 & 7 & 15 & 85 & 7 & 13 & 86 & 3 & 10 \\
\hline F. T. & 85 & 12 & 18 & 90 & 5 & 9 & 90 & 10 & 21 \\
\hline G. M. & 91 & 11 & 21 & 88 & 8 & 19 & 97 & 10 & 16 \\
\hline D. R. & 96 & 20 & 34 & 95 & 22 & 31 & 87 & 14 & 30 \\
\hline L. B. & 94 & 17 & 24 & 94 & 17 & 22 & 90 & 7 & 20 \\
\hline M. R. & 90 & 4 & 9 & 94 & 6 & 10 & 97 & 4 & 10 \\
\hline D. M. & 82 & 12 & 18 & 86 & 11 & 15 & 88 & 6 & 14 \\
\hline R. P. & 100 & 13 & 22 & 97 & 7 & 16 & 111 & 5 & 12 \\
\hline Mean & 90.4 & 12.2 & 19.2 & 92.2 & 10.2 & 17.3 & 92.5 & 7.7 & 16.8 \\
\hline $\mathrm{SE}$ & 1.6 & 1.2 & 2.1 & 1.5 & 1.7 & 2.0 & 2.2 & 1.2 & 1.8 \\
\hline
\end{tabular}

* Control values indicate actual values; $\mathrm{NE}_{1}$ and $\mathrm{NE}_{2}$ values are the increase in mean arterial pressure from the control values during infusion of two doses of norepinephrine: 3 and $6 \mu \mathrm{g} / \mathrm{min}$.

nephrine and angiotensin were insufficient to cause detectable changes in blood pressure or heart rate. The reduction in blood flow to the forearm during both norepinephrine and angiotensin was significantly less during hypoxia than during normoxia (Tables $\mathrm{V}$ and VI).

Effect of hypoxia on blood pressure response to intravenous norepinephrine. Resting mean arterial pressure was not significantly different while breathing air, $12 \%$ oxygen, and $10 \%$ oxygen (Table VII). The increase in blood pressure in response to intravenous norepinephrine was significantly less during hypoxia than during normoxia (Tables VII and VIII).

Effect of hypoxia on calf response to intravenous norepinephrine. Resting calf vascular resistance was not significantly altered $(P>0.05)$ by hypoxia (Fig. 2$)$. The increase in calf vascular resistance during two doses of intravenous norepinephrine was not significantly different during normoxia and hypoxia.

\section{DISCUSSION}

These experiments indicate that hypoxia decreases the constrictor response of forearm resistance vessels to infusions of norepinephrine and angiotensin into the brachial artery. In terms of relative potency, twice the dose of norepinephrine and angiotensin were required during hypoxia to give the same vasoconstriction occurring during normoxia. The absolute levels of flow achieved during infusions of norepinephrine and angiotensin were lower during normoxia than those during hypoxia. The absolute reductions in flow during norepinephrine and angiotensin were similar during normoxia and hypoxia. However, at high levels of resting blood flow the absolute reduction in blood flow was greater (Fig 3), so that similar absolute reduction in flow does not mean that responsiveness did not change because, if this were the case, one would have expected greater reductions in flow at the higher resting flows during hypoxia.

We considered the possibility that shifts of flow within the forearm from skin to muscle during hypoxia might contribute to the decrease in responses to norepinephrine. The response of the hand to norepinephrine was greater than that of the forearm (Fig. 4), indicating greater response of the skin than muscle. However, the shift of flow from skin to muscle during hypoxia appeared to be of small magnitude, particularly during $12 \%$ oxygen, and not sufficient to explain the decrease in forearm responses during hypoxia. The response to angiotensin was similar in the hand and forearm, so that shifts of blood flow from skin to muscle would not account for the diminished response to angiotensin during hypoxia. Therefore, the small shift of flow from skin to muscle within the forearm during hypoxia does not appear to account for the decreased forearm vascular responsiveness to norepinephrine and angiotensin during hypoxia. 

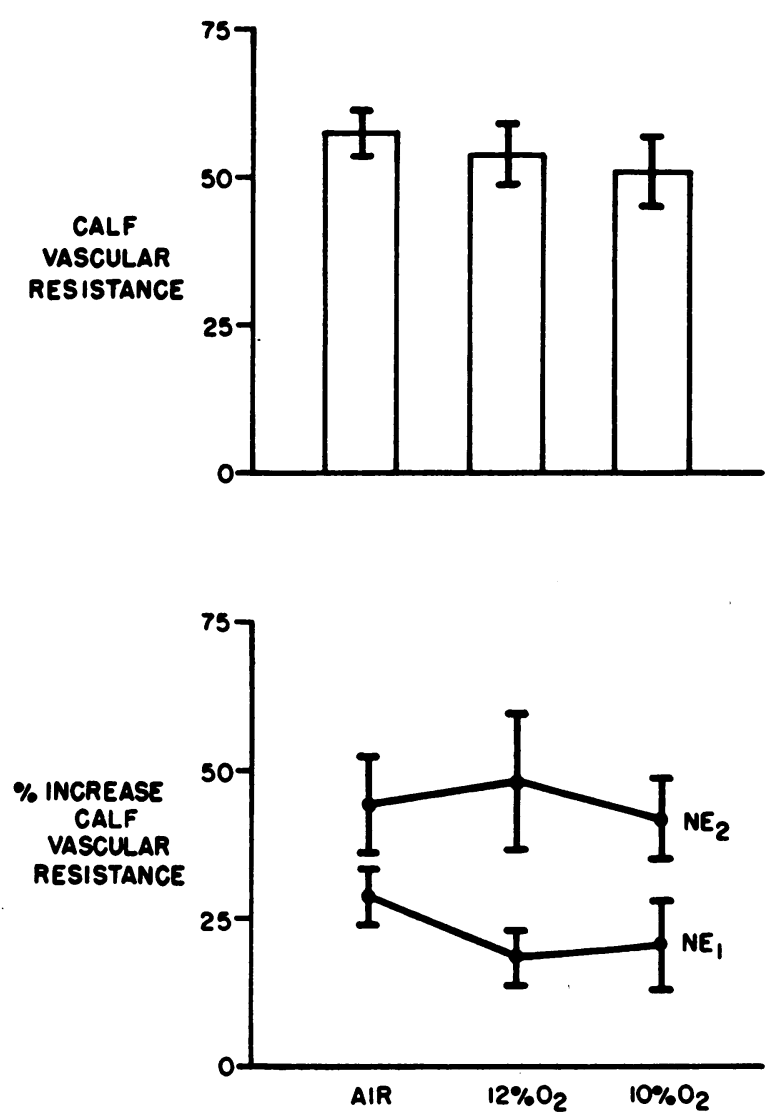

Figure 2 Mean ( $\pm 1 \mathrm{SE}$ ) resting calf vascular resistance in $\mathrm{mm} \mathrm{Hg} / \mathrm{ml} / \mathrm{min} / 100 \mathrm{ml}$ calf (upper half) and per cent increase in calf vascular resistance in response to an intravenous infusion of 3 and $6 \mu \mathrm{g} / \mathrm{min}$ norepinephrine (lower half), while breathing air, $12 \%$ oxygen, and $10 \%$ oxygen.

Hypoxia decreased the response to intravenous as well as intra-arterial norepinephrine, as the increase in mean arterial pressure during intravenous norepinephrine was significantly less during hypoxia than during normoxia. Although the pressor response to intravenous norepinephrine was diminished during hypoxia, the increase in calf vascular resistance during norepinephrine was not significantly different during normoxia and hypoxia. The similar increase in calf vascular resistance, but with a greater increase in distending pressure during normoxia, suggests a greater increase in vasoconstrictor tone during norepinephrine infusion during normoxia than hypoxia.

Detar and Bohr (18) have reported that hypoxia decreases the response of aortic strips to epinephrine, suggesting that hypoxia limits oxidative pathways, with diminished high-energy phosphate production. Whether systemic hypoxia in man actually causes hypoxia in the vascular smooth muscle is not answered at the present time.

The effect of hypoxia in reducing vasoconstrictor responses to norepinephrine, the neurotransmitter released during reflex vasoconstriction, appears to be one mechanism by which hypoxia decreases reflex vasoconstriction. However, it appears that hypoxia decreases reflex vasoconstrictor responses to a greater degree than the responses to norepinephrine, suggesting that hypoxia has additional effects on the reflex vasoconstrictor arc.

\section{III}

\section{Effect of hypoxia and hypocapnia}

\section{METHODS}

We studied 12 healthy men. Responses to lower body negative pressure and the application of ice to the forehead were compared during four conditions.

(a) Normoxia and normocapnia: while breathing air.

(b) Hypoxia and hypocapnia: while breathing $12 \%$ $\mathrm{o:y} \mathrm{y}_{\mathrm{o}} \mathrm{e}: 1$.

TABLE VIII

Analysis of Variance of Mean Arterial Pressure Responses to Intravenous Norepinephrine While Breathing Air, $12 \%$ Oxygen, and 10\% Oxygen*

\begin{tabular}{|c|c|c|c|c|c|c|c|c|}
\hline \multirow[b]{2}{*}{ Source of variation } & \multicolumn{4}{|c|}{$\begin{array}{l}\text { Effect of oxygen on resting } \\
\text { mean pressure }\end{array}$} & \multicolumn{4}{|c|}{$\begin{array}{l}\text { Effect of oxygen on increase in mean } \\
\text { pressure during norepinephrine }\end{array}$} \\
\hline & df & $\begin{array}{c}\text { Mean } \\
\text { square }\end{array}$ & F & $P$ & df & $\begin{array}{l}\text { Mean } \\
\text { square }\end{array}$ & F & $P$ \\
\hline Subjects & 11 & 85 & & & 11 & 147 & & \\
\hline Oxygen & 2 & 15.7 & 1.09 & $>0.20$ & 2 & 75.5 & 4.98 & $<0.025$ \\
\hline Dose & & & & & 1 & 1073.0 & 108.05 & $<0.001$ \\
\hline Error & 22 & 14.4 & & & 22 & 9.0 & & \\
\hline
\end{tabular}

* Analysis of variance was done on the absolute values of resting mean arterial pressure and on the absolute values for change in mean pressure during norepinephrine.

$\ddagger$ Oxygen refers to variation in resting pressure and responses to norepinephrine while breathing air, $12 \%$ oxygen, and $10 \%$ oxygen. 

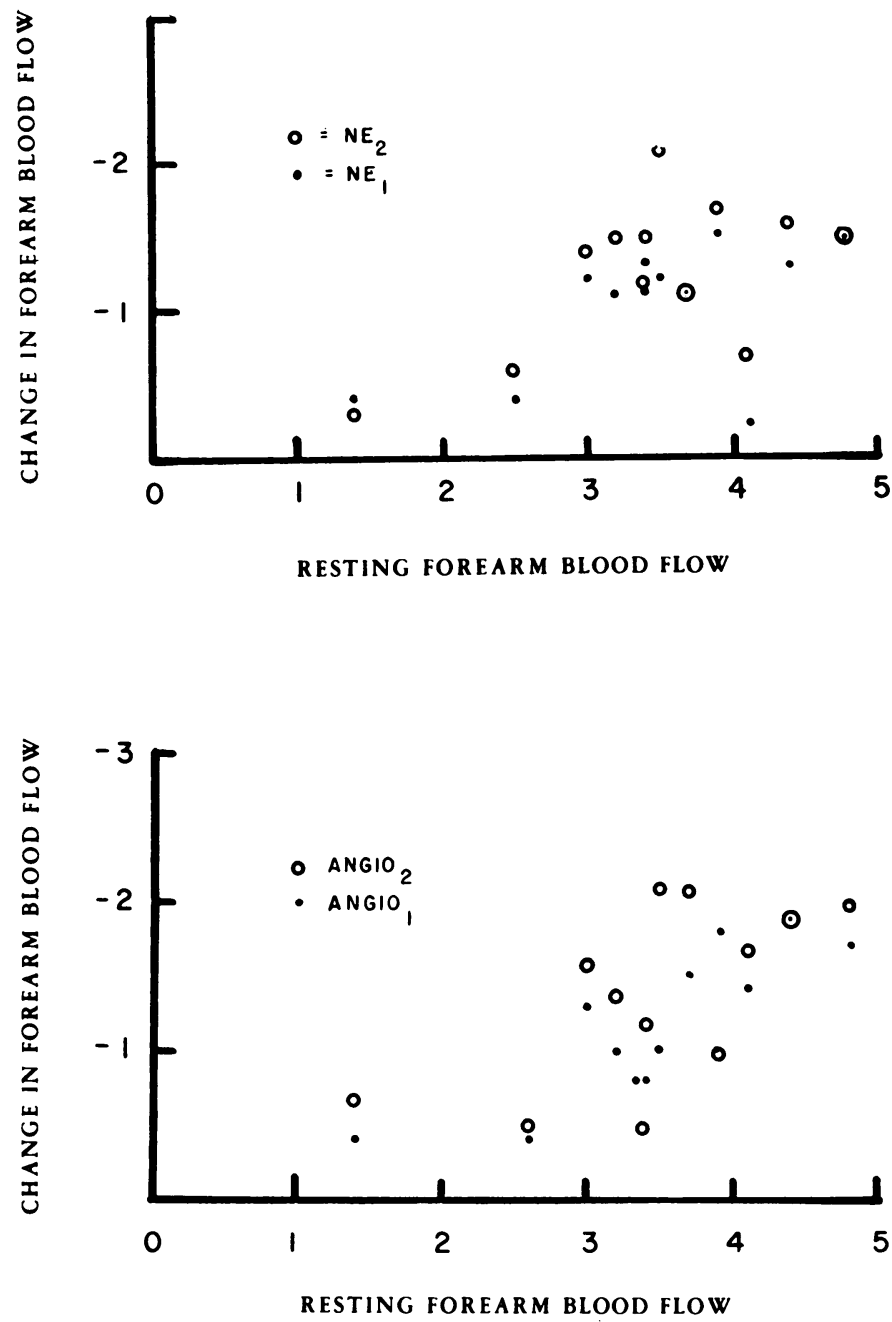

Figure 3 Relationship between resting forearm blood flow and the decrease in forearm flow (expressed in $\mathrm{ml} / \mathrm{min} / 100 \mathrm{ml}$ forearm) in response to 75 and $150 \mathrm{~m} \mu \mathrm{g} / \mathrm{min}$ of norepinephrine (upper half) and angiotensin (lower half) infused into the brachial artery, while breathing air. A positive correlation exists between resting forearm flow and the decrease in forearm flow: in response to 75 $\mathrm{m} \mu \mathrm{g}$ norepinephrine $\left(\mathrm{NE}_{1}\right) \quad r=0.54(P>0.05)$; in response to $150 \mathrm{~m} \mu \mathrm{g}$ norepinephrine $\left(\mathrm{NE}_{2}\right) \quad r=0.58(P=0.05)$; in response to $75 \mathrm{~m} \mu \mathrm{g}$ angiotensin (Angio $) r=0.83(P<0.01)$; in response to $150 \mathrm{~m} \mu \mathrm{g}$ angiotensin (Angio. $) r=0.62(P<0.05)$.

(c) Hypoxia and normocapnia: while breathing $10.5 \%$ oxygen with carbon dioxide replacement. End-tidal $\mathrm{CO}_{2}$ was measured directly by an LB-1 infrared $\mathrm{CO}_{2}$ analyzer, with continuous sampling at the mouthpiece. Additional carbon dioxide was added to the inspired $10.5 \%$ oxygen at flow rates sufficient to maintain end-tidal $\mathrm{CO}_{2}$ at values similar to those obtained while breathing air. $300-500 \mathrm{cc}$ of carbon dioxide was necessary to maintain normal end-tidal $\mathrm{CO}_{2}$. Since addition of carbon dioxide stimulates further hyperventilation and increases $\mathrm{PO}_{2}$ during hypoxia (14), $10.5 \%$ oxygen was inspired during carbon dioxide replacement in an attempt to approximate the $\mathrm{Po}_{2}$ during $12 \%$ oxygen.

(d) Normoxia and hypocapnia: during hyperventilation while breathing room air. The subject adjusted his respiration to maintain an end-tidal $\mathrm{CO}_{2}$ similar to the level achieved while breathing $12 \%$ oxygen.

In addition to continuously monitoring end-tidal $\mathrm{CO}_{2}$, alveolar samples were obtained with a Rahn-Otis sampling valve after breathing each gas mixture for 6 and $14 \mathrm{~min}$. The alveolar gas samples were analyzed for $\mathrm{Po}_{2}$ and $\mathrm{PCO}_{2}$ 

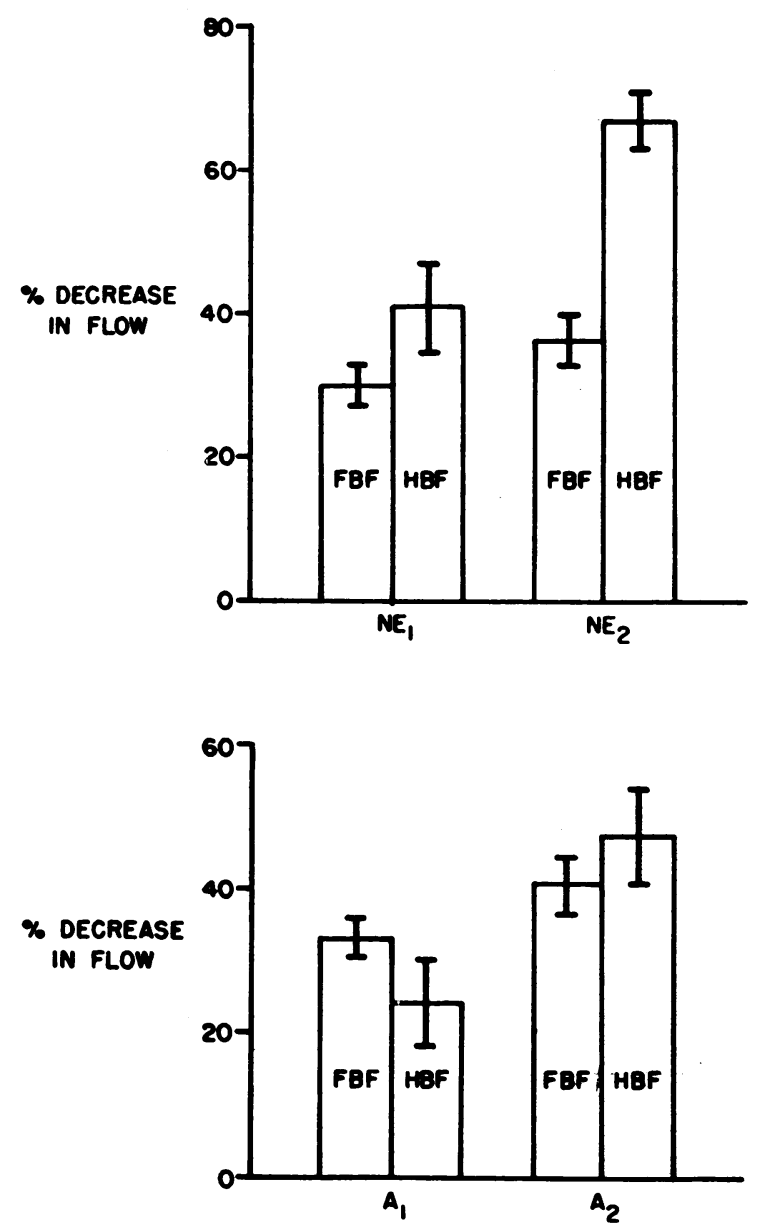

Figure 4 Mean per cent decrease in forearm (FBF) and hand (HBF) blood flow in response to 75 and $150 \mathrm{~m} \mu \mathrm{g} / \mathrm{min}$ of norepinephrine (upper half) and angiotensin (lower half) infused into the brachial artery. Measurements were obtained while breathing room air.

with an IL Ultramicro Gas Analyzer. Expiratory minute volume was collected and measured.

Forearm and hand blood flow were measured with water plethysmographs, and blood pressure determined by auscultation.

\section{RESULTS}

Alveolar oxygen and carbon dioxide tensions. Alveolar $\mathrm{PCO}_{2}$ was reduced to virtually identical levels while breathing $12 \%$ oxygen and during hyperventilation while breathing air (Table IX). Alveolar $\mathrm{PCO}_{2}$ was similar while breathing air and while breathing $10.5 \%$ oxygen with carbon dioxide replacement. The alveolar $\mathrm{Po}_{2}$ was reduced to similar levels while breathing $12 \%$ oxygen and while breathing $10.5 \%$ oxygen with carbon dioxide replacement.
Effect of hypoxia and hypocapnia on blood pressure and vascular resistance. Mean arterial pressure and forearm vascular resistance were not significantly altered by hypoxia or hypocapnia (Tables X and XI). Hand blood flow was significantly greater $(P<0.05)$ while breathing air $(20.4 \pm 2.5 \mathrm{SE})$ than during either the hypoxic or hypocapneic periods (14.8 \pm 2.6 during $12 \%$ oxygen, $16.2 \pm 2.5$ during $10.5 \mathrm{O}_{2}$ with $\mathrm{CO}_{2}$ replacement, and $15.9 \pm 2.4$ during hyperventilation.).

Effect of hypoxia and hypocapnia on responses to lower body negative pressure. Lower body negative pressure causes a similar fall in mean arterial pressure during hypoxia with and without carbon dioxide replacement (Tables X and XII). The lower body negative pressure caused a negligible fall in mean arterial pressure during the hypocapnia of hyperventilation. Therefore, hypocapnia appears to contribute minimally to the hypotensive effect of lower body negative pressure during acute hypoxia. The increase in forearm vascular resistance in response to lower body negative pressure was diminished during hypoxia with and without carbon dioxide replacement (Tables XI and XII).

Effect of hypoxia and hypocapnia on responses to application of ice to the forehead. The increase in mean arterial pressure during application of ice to the forehead was not significantly altered during hypoxia or hypocapnia (Tables X and XIII). The increase in forearm vascular resistance which occurs during application of ice to the forehead while breathing air was markedly reduced during hypoxia, with and without carbon dioxide replacement, and by the hypocapnia of hyperventilation (Tables XI and XIII).

\section{DISCUSSION}

In a previous study (13), addition of carbon dioxide to the inspired mixture during exposure to acute hypoxia decreased the forearm vasodilatation which occurs during severe hypoxia, suggesting an important role of hypocapnia in the cardiovascular response to hypoxia. However, addition of carbon dioxide stimulates further hyperventilation and significantly increases the $\mathrm{Po}_{2}$ during hypoxia (14). When hypocapnia was eliminated during acute hypoxia without a change in $\mathrm{Po}_{2}$, the circulatory response to acute hypoxia was not altered (14).

These experiments indicate that hypoxia, but not hypocapnia, decreases the vasoconstrictor response to lower body negative pressure, with a fall in arterial pressure. In contrast to the primary role of oxygen in the response to lower body suction, both hypocapnia and hypoxia decreased the forearm vasoconstrictor response to the application of ice to the forehead. The diminished vasoconstirctor response to norepinephrine during hypoxia appears to be unrelated to hypocapnia. In Part II 
TABLE IX

Alveolar Carbon Dioxide and Oxygen Tension*

\begin{tabular}{|c|c|c|c|c|c|c|c|c|}
\hline \multirow[b]{2}{*}{ Subject } & \multicolumn{4}{|c|}{$\mathrm{PcO}_{2}$} & \multicolumn{4}{|c|}{$\mathrm{Po}_{2}$} \\
\hline & Air & Hyper & $12 \% \mathrm{O}_{2}$ & $\begin{array}{l}10.5 \% \mathrm{O}_{2} \\
\text { and } \mathrm{CO}_{2}\end{array}$ & Air & Hyper & $12 \% \mathrm{O}_{2}$ & $\begin{array}{l}10.5 \% \mathrm{O}_{2} \\
\text { and } \mathrm{CO}_{2}\end{array}$ \\
\hline & \multicolumn{4}{|c|}{$m m \mathrm{Hg}$} & \multicolumn{4}{|c|}{$m m \mathrm{Hg}$} \\
\hline J. R. & 37.8 & 36.0 & 36.8 & 40.8 & 104.3 & 109.7 & 54.8 & 56.7 \\
\hline L. H. & 40.1 & 35.7 & 37.4 & 39.0 & 103.3 & 108.1. & 58.0 & 58.6 \\
\hline D. 0 . & 41.5 & 32.0 & 32.8 & 40.1 & 98.4 & 108.8 & 50.7 & 50.0 \\
\hline T. T. & 35.0 & 31.2 & 28.6 & 37.0 & 114.2 & 111.2 & 63.6 & 50.0 \\
\hline R. J. & 39.4 & 37.5 & 34.0 & 38.0 & 104.6 & 107.2 & 54.6 & 52.4 \\
\hline R. R. & 37.8 & 29.0 & 35.0 & 41.0 & 107.0 & 115.6 & 49.8 & 53.4 \\
\hline R. A. & 42.6 & 32.5 & 33.5 & 37.7 & 107.6 & 112.9 & 52.4 & 55.8 \\
\hline B. S. & 36.0 & 33.4 & 29.2 & 39.6 & 111.8 & 113.8 & 57.6 & 52.4 \\
\hline E. W. & 37.8 & 31.8 & 31.6 & 37.6 & 105.4 & 112.4 & 54.2 & 51.6 \\
\hline D. R. & 36.7 & 35.6 & 33.8 & 41.4 & 114.6 & 112.4 & 54.0 & 55.2 \\
\hline J. S. & 35.8 & 30.0 & 29.2 & 39.8 & 127.0 & 120.0 & 54.5 & 53.2 \\
\hline G. M. & 33.9 & 29.4 & 30.0 & 37.2 & 114.2 & 119.6 & 54.7 & 53.6 \\
\hline Mean & 37.9 & 32.8 & 32.7 & 39.1 & 109.4 & 112.6 & 54.9 & 53.6 \\
\hline SE & 0.8 & 0.8 & 0.9 & 0.5 & 2.2 & 1.2 & 1.0 & 0.8 \\
\hline
\end{tabular}

* Hyper refers to hyperventilation while breathing air. $10.5 \% \mathrm{O}_{2}$ and $\mathrm{CO}_{2}$ refers to breathing $10.5 \%$ oxygen with replacement of carbon dioxide to normal values. Each value represents the average of two values obtained during each condition.

of this study, in 4 of the 24 periods of exposure to hypoxia the arterial blood $\mathrm{PcO}_{2}$ was higher during hypoxia than while breathing air (Table IV) and in all four the vasoconstrictor response to intra-arterial norepinephrine was reduced during hypoxia. It therefore appears that, although hypocapnia may alter the response to some neurogenic stimuli, the reduction in oxygen is the primary mechanism for decreased vascular responsiveness during acute hypoxia.

The levels of hyperventilation used in this study did

TABLE X

Mean Arterial Blood Pressure in Response to Lower Body Negative Pressure and Ice on Forehead during Alteration of Oxygen and Carbon Dioxide*

\begin{tabular}{|c|c|c|c|c|c|c|c|c|c|c|c|c|}
\hline \multirow[b]{2}{*}{ Subject } & \multicolumn{3}{|c|}{ Air } & \multicolumn{3}{|c|}{ Hyperventilation } & \multicolumn{3}{|c|}{$12 \% \mathrm{O}_{2}$} & \multicolumn{3}{|c|}{$10.5 \% \mathrm{O}_{2}$ and $\mathrm{CO}_{2}$} \\
\hline & Con & LBNP & Ice & Con & LBNP & Ice & Con & LBNP & Ice & Con & LBNP & Ice \\
\hline & \multicolumn{3}{|c|}{$m m \mathrm{Hg}$} & \multicolumn{3}{|c|}{$m m \mathrm{Hg}$} & \multicolumn{3}{|c|}{$m m \mathrm{Hg}$} & \multicolumn{3}{|c|}{$m m \mathrm{Hg}$} \\
\hline J. R. & 85 & 85 & 103 & 88 & 89 & 90 & 88 & 82 & 93 & 89 & 87 & 102 \\
\hline L. H. & 79 & 77 & 85 & 80 & 85 & 90 & 80 & 81 & 90 & 84 & 83 & 88 \\
\hline D. $O$. & 102 & 95 & 115 & 103 & 100 & 117 & 99 & 89 & 108 & 97 & 88 & 112 \\
\hline T. T. & 87 & 89 & 102 & 85 & 86 & 102 & 87 & 88 & 110 & 83 & 84 & 103 \\
\hline R. J. & 84 & 82 & 95 & 87 & 84 & 95 & 86 & 85 & 95 & 84 & 83 & 92 \\
\hline R. R. & 82 & 81 & 102 & 83 & 83 & 105 & 83 & 74 & 90 & 87 & 80 & 88 \\
\hline R. A. & 90 & 89 & 100 & 91 & 83 & 105 & 90 & 86 & 110 & 93 & 87 & 103 \\
\hline B. S. & 86 & 89 & 100 & 85 & 85 & 97 & 85 & 77 & 93 & 80 & 76 & 87 \\
\hline E. W. & 81 & 85 & 100 & 93 & 93 & 102 & 88 & 84 & 95 & 90 & 93 & 102 \\
\hline D. R. & 78 & 74 & 90 & 83 & 76 & 92 & 86 & 75 & 90 & 80 & 73 & 90 \\
\hline J. S. & 94 & 99 & 123 & 97 & 96 & 125 & 93 & 87 & 110 & 95 & 87 & 113 \\
\hline G. M. & 92 & 95 & 113 & 94 & 94 & 113 & 94 & 90 & 120 & 107 & 98 & 120 \\
\hline Mean & 86.7 & 86.7 & 102.3 & 89.1 & 87.8 & 102.8 & 88.2 & 83.2 & 100.3 & 89.1 & 84.9 & 100.0 \\
\hline SE & 2.0 & 2.2 & 3.0 & 1.9 & 1.9 & 3.2 & 1.5 & 1.6 & 3.0 & 2.3 & 2.0 & 3.2 \\
\hline
\end{tabular}

* See footnote to Table I and IX. 
TABLE XI

Forearm Vascular Resistance in Response to Lower Body Negative Pressure and Ice on the Forehead during Alteration of Oxygen and Carbon Dioxide*

\begin{tabular}{|c|c|c|c|c|c|c|c|c|c|c|c|c|}
\hline \multirow[b]{2}{*}{ Subject } & \multicolumn{3}{|c|}{ Air } & \multicolumn{3}{|c|}{ Hyperventilation } & \multicolumn{3}{|c|}{$12 \% \mathrm{O}_{2}$} & \multicolumn{3}{|c|}{$10.5 \% \mathrm{O}_{2}+\mathrm{CO}_{2}$} \\
\hline & Con & LBNP & Ice & Con & LBNP & Ice & Con & LBNP & Ice & Con & LBNP & Ice \\
\hline & \multicolumn{3}{|c|}{$\mathrm{mm} \mathrm{Hg} / \mathrm{ml} / \mathrm{min} / 100 \mathrm{ml}$} & \multicolumn{3}{|c|}{$\mathrm{mm} \mathrm{Hg} / \mathrm{ml} / \mathrm{min} / 100 \mathrm{ml}$} & \multicolumn{3}{|c|}{$\mathrm{mm} \mathrm{Hg} / \mathrm{ml} / \mathrm{min} / 100 \mathrm{ml}$} & \multicolumn{3}{|c|}{$\mathrm{mm} \mathrm{Hg} / \mathrm{ml} / \mathrm{min} / 100 \mathrm{ml}$} \\
\hline J. R. & 8.6 & 11.0 & 17.8 & 12.6 & 18.5 & 12.7 & 12.1 & 13.4 & 11.1 & 8.7 & 11.6 & 17.9 \\
\hline L. H. & 11.0 & 20.3 & 15.7 & 12.5 & 21.2 & 16.1 & 11.1 & 17.6 & 15.0 & 11.7 & 16.0 & 13.8 \\
\hline D. $\mathrm{O}$. & 17.3 & 20.2 & 19.5 & 18.1 & 27.0 & 23.9 & 16.2 & 18.5 & 16.9 & 12.3 & 9.2 & 14.4 \\
\hline T. T. & 31.1 & 46.8 & 48.6 & 31.5 & 57.3 & 42.5 & 30.0 & 38.3 & 36.7 & 23.7 & 33.6 & 32.2 \\
\hline R. J. & 31.1 & 41.0 & 33.9 & 36.2 & 49.4 & 22.1 & 23.9 & 30.4 & 27.9 & 28.0 & 34.6 & 30.7 \\
\hline R. R. & 23.4 & 31.2 & 44.3 & 30.7 & 46.1 & 36.2 & 22.4 & 25.5 & 22.0 & 30.0 & 30.8 & 29.3 \\
\hline R. A. & 14.3 & 26.2 & 45.5 & 13.4 & 22.4 & 30.0 & 16.1 & 26.1 & 47.8 & 16.6 & 25.6 & 57.2 \\
\hline B. S. & 24.6 & 111.2 & 29.4 & 19.8 & 42.5 & 20.2 & 19.8 & 30.8 & 13.5 & 18.6 & 34.5 & 10.7 \\
\hline E. W. & 38.6 & 85.0 & 50.0 & 46.5 & 77.5 & 60.0 & 24.4 & 38.2 & 29.7 & 26.5 & 56.4 & 35.2 \\
\hline D. R. & 22.9 & 41.1 & 21.4 & 31.9 & 69.1 & 32.9 & 30.7 & 34.1 & 30.0 & 29.6 & 45.6 & 30.0 \\
\hline J. S. & 25.4 & 47.1 & 58.6 & 32.3 & 60.0 & 40.3 & 32.1 & 37.8 & 42.3 & 30.6 & 29.0 & 33.2 \\
\hline G. M. & 30.7 & 41.3 & 40.4 & 34.8 & 49.5 & 20.5 & 30.3 & 34.6 & 25.0 & 34.5 & 28.0 & 21.8 \\
\hline Mean & 23.2 & 43.5 & 35.4 & 26.7 & 45.0 & 29.8 & 22.4 & 28.8 & 26.5 & 22.6 & 28.8 & 27.2 \\
\hline $\mathrm{SE}$ & 2.7 & 8.2 & 4.2 & 3.2 & 5.6 & 3.9 & 2.1 & 2.5 & 3.4 & 2.5 & 3.4 & 3.7 \\
\hline \multicolumn{13}{|l|}{$\begin{array}{l}\text { Mean of indi- } \\
\text { vidual } \%\end{array}$} \\
\hline change from Con & & 84.7 & 63.9 & & 68.9 & 18.1 & & 30.8 & 22.3 & & 29.9 & 32.7 \\
\hline SE of $\%$ change & & 25.8 & 19.3 & & 7.7 & 12.2 & & 6.1 & 16.9 & & 10.3 & 22.1 \\
\hline
\end{tabular}

* See footnote to Table X.

not alter resting forearm resistance or blood pressure. Previous studies have indicated that the hypocapnia associated with hyperventilation increases forearm blood flow $(19,20)$. However, those studies employed levels of hyperventilation far greater than ours, in which minute volume increased from an average of 5.6 liters/ min while breathing air to 6.8 liters/min during hyperventilation.

TABLE XII

Analysis of Variance and Calculation of Critical Difference of Responses to Lower Body Negative Pressure during Alteration of Oxygen and Carbon Dioxide*

\begin{tabular}{|c|c|c|c|c|c|c|c|c|}
\hline \multirow[b]{2}{*}{ Source of variation } & \multicolumn{4}{|c|}{$\begin{array}{l}\text { Effect of } \mathrm{O}_{2} \text { and } \mathrm{CO}_{2} \text { on change } \\
\text { in mean arterial pressure } \\
\text { during negative pressure }\end{array}$} & \multicolumn{4}{|c|}{$\begin{array}{c}\text { Effect of } \mathrm{O}_{2} \text { and } \mathrm{CO}_{2} \text { on } \% \text { change } \\
\text { in forearm vascular resistance } \\
\text { during negative pressure }\end{array}$} \\
\hline & df & $\begin{array}{c}\text { Mean } \\
\text { square }\end{array}$ & $\mathrm{F}$ & $P$ & df & $\begin{array}{r}\text { Mean } \\
\text { square }\end{array}$ & F & $P$ \\
\hline Subjects & 11 & 32.5 & & & 11 & 5612 & & \\
\hline Treatments $\ddagger$ & 3 & 68.8 & 8.02 & $<0.001$ & 3 & 9144 & 5.70 & $<0.005$ \\
\hline Error & 33 & 8.57 & & & 33 & 1605 & & \\
\hline
\end{tabular}

* To avoid doing multiple $t$ test analyses on the same data, critical difference was calculated using the mean square error term, with $t_{0.05}$ taken from a table by Tukey for the number of means involved (21). The critical difference for change in mean arterial pressure during lower body negative pressure was $3.2 \mathrm{~mm} \mathrm{Hg}$ : from Table $\mathrm{X}$ it is evident that the response during air differs significantly from the response during $12 \%$ oxygen and from $10.5 \%$ oxygen with $\mathrm{CO}_{2}$, and that the response during $12 \%$ oxygen differs from that during hyperventilation. The critical difference for change in forearm vascular resistance during lower body negative pressure was 44.3. From Table XI the response during air differs significantly from the response during $12 \%$ oxygen and from $10.5 \%$ oxygen with $\mathrm{CO}_{2}$.

$\ddagger$ Treatment refers to variation among responses to lower body negative pressure while breathing air, $12 \%$ oxygen, $10.5 \%$ oxygen with replacement of $\mathrm{CO}_{2}$, and during hyperventilation. 
TABLE XIII

Analysis of Variance and Calculation of Critical Difference of Responses to Ice on the Forehead during Alteration of Oxygen and Carbon Dioxide*

\begin{tabular}{|c|c|c|c|c|c|c|c|c|}
\hline \multirow[b]{2}{*}{ Source of variation } & \multicolumn{4}{|c|}{$\begin{array}{c}\text { Effect of } \mathrm{O}_{2} \text { and } \mathrm{CO}_{2} \text { on changes } \\
\text { in mean arterial pressure } \\
\text { during ice }\end{array}$} & \multicolumn{4}{|c|}{$\begin{array}{c}\text { Effect of } \mathrm{O}_{2} \text { and } \mathrm{CO}_{2} \text { on } \% \text { change } \\
\text { in forearm vascular resistance } \\
\text { during ice }\end{array}$} \\
\hline & df & $\begin{array}{l}\text { Mean } \\
\text { square }\end{array}$ & $\mathrm{F}$ & $P$ & df & $\begin{array}{l}\text { Mean } \\
\text { square }\end{array}$ & $\mathbf{F}$ & $P$ \\
\hline Subjects & 11 & 96.3 & & & 11 & 12,587 & & \\
\hline Treatments $\ddagger$ & 3 & 50.8 & 2.01 & $>0.05$ & 3 & 5,152 & 5.24 & $<0.005$ \\
\hline Error & 33 & 25.3 & & & 33 & 983 & & \\
\hline
\end{tabular}

* See footnote to Table XII. Critical difference was not calculated for change in mean arterial pressure during ice on the forehead since analysis of variance indicated no significant differences were present. The critical difference for change in forearm vascular resistance during ice on the forehead was 34.7. From Table XI the response during air differs significantly from the response during $12 \%$ oxygen and from hyperventilation. $\ddagger$ Treatment refers to variation among responses to ice on the forehead while breathing air, $12 \%$ oxygen, $10.5 \%$ oxygen with replacement of $\mathrm{CO}_{2}$, and during hyperventilation.

It was again evident in these experiments, as in the other experiments in this report, that levels of hypoxia which do not consistently alter resting vascular resistance and arterial pressure nevertheless markedly decrease vasoconstrictor responsiveness. Although it is clear that resistance vessels exhibit significant "resting" tone, the finding that hypoxia decreases vasoconstrictor responses without altering vascular resistance appears to support the hypothesis (18) that oxygen is more likely to be rate limiting in the vascular smooth muscle during vasoconstriction.

\section{ACKNOWLEDGMENTS}

We wish to thank Doctors Milton Landowne and Francois M. Abboud for their valuable discussion and criticisms, Mr. Robert Petroff and Albert Williams for their technical assistance, and Dr. R. Yale Hicks and Miss Ella Munro for their statistical assistance.

\section{REFERENCES}

1. Heistad, D. D., and R. C. Wheeler. 1969. Effect of acute hypoxia on neurogenic vasoconstriction in man. Clin. Res. $17: 245$.

2. Kenmure, A. C. F., W. R. Murdoch, A. D. Beattie, J. C. B. Marshall, and A. J. V. Cameron. 1968. Circulatory and metabolic effects of oxygen in myocardial infarction. Brit. Med. J. 4: 360 .

3. Skinner, N. S., and J. C. Costin. 1969. Role of $\mathrm{O}_{2}$ and $\mathrm{K}^{+}$in abolition of sympathetic vasoconstriction in dog skeletal muscle. Amer. J. Physiol. 217: 438.

4. Gowdey, C. W. 1966. The autonomic nervous system in hypoxia. In Proceedings of the International Symposium on the Cardiovascular and Respiratory Effects of $\mathrm{Hy}$ poxia. J. D. Hatcher and D. B. Jenning, editors. Hafner Publishing Co., Inc., New York. 232.
5. Marticorena, E., L. Ruiz, J. Severino, J. Galvez, and D. Penaloza. 1969. Systemic blood pressure in white men born at sea level: changes after long residence at high altitudes. Amer. J. Cardiol. 23: 364.

6. Abboud, F. M., and J. W. Eckstein. 1966. Reflex vasoconstrictor and vasodilator responses in man. Circ. Res. 18 (Suppl. I.) : 96.

7. Brown, E., J. S. Goei, A. D. M. Greenfield, and G. C. Plassaras. 1966. Circulatory responses to simulated gravitational shifts of blood in man induced by exposure of the body below the iliac crests to sub-atmospheric pressure. J. Physiol. (London). 183: 607.

8. Wilkins, R. W., and L. W. Eichna. 1941. Blood flow to the forearm and calf. Johns Hopkins Med. J. 68: 425.

9. Crossley, R. J., A. D. M. Greenfield, G. C. Plassaras, and D. Stephens. 1966. The interrelation of thermoregulatory and baroreceptor reflexes in the control of the blood vessels in the human forearm. J. Physiol. (London). 183: 628.

10. Zelis, R., G. D. Beiser, D. T. Mason, S. E. Epstein, and E. Braunwald. 1968. The participation of both skin and muscle resistance vessels in baroreceptor reflexes. Clin. Res. 16: 254.

11. Landowne, M., A. J. Pratt, and H. W. Fisher. 1955. Analysis of radial intra-arterial pressures. Fed. Proc. 14: 90 .

12. Abramson, D. I., H. Landt, and J. E. Benjamin. 1943. Peripheral vascular response to acute anoxia. Arch. Intern. Med. 71: 583 .

13. Black, J. E., and I. C. Roddie. 1958. The mechanism of the changes in forearm vascular resistance during hypoxia. J. Physiol. (London). 143: 226.

14. Richardson, D. W., H. A. Kontos, W. Shapiro, and J. L. Patterson, Jr. 1966. Role of hypocapnia in the circulatory responses to acute hypoxia in man. J. Appl. Physiol. 21: 22.

15. Richardson, D. W., H. A. Kontos, A. J. Raper, and J. L. Patterson, Jr. 1967. Modification by betaadrenergic blockade of the circulatory responses to acute hypoxia in man. J. Clin. Invest. 46: 77. 
16. Abramson, D. I. 1967. Circulation in the Extremities. Academic Press Inc., New York. 102.

17. Wood, J. E. 1965. The Veins: Normal and Abnormal Function. Little, Brown, and Company, Boston. 62.

18. Detar, R.. and D. F. Bohr. 1968. Oxygen and vascular smooth muscle contraction. Amer. J. Physiol. 214: 241.

19. Brick, I., K. J. Hutchinson, and I. C. Roddie. 1966. The effect of betaadrenergic receptor blockade on the vasodilator response in the forearm to voluntary hyperventilation. J. Physiol. (London). 187: 645.

20. Coffman, J. D., and P. Kelly. 1966. Hyperventilation and human calf blood flow. Amer. J. Physiol. 211: 1255.

21. Li, C. C. 1964. Introduction to Experimental Statistics. McGraw-Hill Book Company, New York. 425. 